九州大学学術情報リポジトリ

Kyushu University Institutional Repository

\title{
Campylobacter jejuni DNA-binding protein from starved cells in Guillain-Barré syndrome patients
}

\section{Kawamura, Nobutoshi}

Department of Neurology, Neurological Institute, Graduate School of Medical Sciences, Kyushu University

Piao, Hua

Department of Neurology, Neurological Institute, Graduate School of Medical Sciences, Kyushu University

Minohara, Motozumi

Department of Neurology, Neurological Institute, Graduate School of Medical Sciences, Kyushu University

Matsushita, Takuya

Department of Neurology, Neurological Institute, Graduate School of Medical Sciences, Kyushu University

他

http://hdl. hand le. net/2324/25650

出版情報: Journal of Neuroimmunology. 240/241, pp.74-78, 2011-12-15. Elsevier バージョン:

権利関係: (C) 2011 Elsevier B.V. 


\section{Campylobacter jejuni DNA-binding protein from starved cells in}

\section{Guillain-Barré syndrome patients}

Nobutoshi Kawamura $^{\text {a, }}$, Hua Piao ${ }^{\text {a, }}$, Motozumi Minohara ${ }^{\text {a }}$, Takuya Matsushita ${ }^{\text {a }}$, Susumu Kusunoki ${ }^{b}$, Hiroshi Matsumoto ${ }^{\mathrm{c}}$, Kazuhiro Ikenaka ${ }^{\mathrm{d}}$, Yoshimitsu Mizunoe ${ }^{\mathrm{e}}$, and Jun-ichi Kira ${ }^{\text {a }}$.

${ }^{a}$ Department of Neurology, Neurological Institute, Graduate School of Medical Sciences, Kyushu University, Fukuoka, Japan.

${ }^{\mathrm{b}}$ Department of Neurology, Kinki University School of Medicine, Osaka, Japan.

${ }^{\mathrm{c}}$ Matsumoto Pediatric Clinic, Anjyo, Japan.

${ }^{\mathrm{d}}$ Division of Neurobiology and Bioinformatics, National Institute for Physiological Sciences, Okazaki, Japan.

${ }^{\mathrm{e}}$ Department of Bacteriology, Jikei University School of Medicine, Tokyo, Japan.

${ }^{1}$ These authors contributed equally to this work.

Address correspondence and reprint requests to: Dr. Jun-ichi Kira, Department of Neurology, Neurological Institute, Graduate School of Medical Sciences, Kyushu University, Fukuoka 812-8582, Japan. E-mail: kira@neuro.med.kyushu-u.ac.jp Tel: +81-92-642-5340; Fax: +81-92-642-5352. 
Word count for the abstract: 239 words

Word count for the text: 2,302 words

Word count for the title including spaces: 95 characters

Number of references: 24 references

Number of figures: 3 figures

Keywords: Acute motor axonal neuropathy (AMAN); antibody; Campylobacter jejuni; $C$. jejuni DNA-binding protein from starved cells (C-Dps); Guillain-Barré syndrome (GBS) 


\section{ABSTRACT}

Campylobacter jejuni (C. jejuni) enteritis is frequently associated with an axonal form of Guillain-Barré syndrome (GBS). This condition presents with prominent axonal degeneration but minimal lymphocytic infiltration, suggesting an involvement of non-immune system factors. We recently reported that a $C$. jejuni DNA-binding protein from starved cells (C-Dps) induces paranodal myelin detachment and axonal degeneration through binding with sulfatide in vivo. Here, we aimed to investigate invasion of C-Dps into hosts with C. jejuni-related GBS. We studied antibody responses to recombinant C-Dps by ELISA and the presence of C-Dps by sandwich ELISA on blood samples from 42 patients with GBS (including 24 with $C$. jejuni-related disease), 148 with other inflammatory neurologic diseases (OIND), 11 with $C$. jejuni enteritis, and 55 healthy controls (HC). Antibodies against C-Dps in sera were significantly more common in $C$. jejuni-related GBS patients $(15 / 24,62.5 \%)$ than in $\mathrm{HC}(0 / 55,0 \%)$ or patients with OIND $(0 / 148,0 \%)$ or $C$. jejuni enteritis $(1 / 11,9 \%)$, suggesting a heavier exposure to C-Dps in $C$. jejuni-related GBS patients. C-Dps was detected in sera from C. jejuni-related GBS patients $(5 / 27,14.8 \%)$ but not from $\mathrm{HC}(0 / 21)$, patients with GBS following respiratory tract infection (0/16), or those with $C$. jejuni enteritis $(0 / 5)$. The frequency of positivity for C-Dps in the sera was significantly higher in C. jejuni-related GBS patients than in HC. These findings suggest that C-Dps invades the hosts and may potentially contribute to the peripheral nerve damage in $C$. jejuni-related GBS. 


\section{INTRODUCTION}

Guillain-Barré syndrome (GBS) is primarily considered to be an inflammatory demyelinating neuropathy; however, prominent axonal involvement is frequently seen in GBS patients following infection by Campylobacter jejuni (C. jejuni) (Ho TW et al., 1995). Electrophysiologically, this axonal form of GBS, termed acute motor axonal neuropathy (AMAN) (Griffin JW et al., 1996), is characterized by a simple reduction of compound muscle action potentials without conduction delay (Kuwabara S et al., 2004; Hiraga A et al., 2005). Pathologically, Wallerian-like degeneration and infiltration of periaxonal macrophages are prominent features, while demyelination and lymphocytic infiltration are minimal or even lacking (Griffin JW et al., 1995).

In this condition, anti-GM1 ganglioside antibody is hypothesized to be pathogenic through molecular mimicry between human GM1 ganglioside and C. jejuni lipo-oligosaccharide (Ariga T and Yu RK, 2005). The reproduction of clinical and pathological components of the disease by passive transfer of anti-GM1 antibodies to experimental animals has been reported (Hirota N et al., 1997; Sheikh KA et al., 2004; Susuki K et al., 2007; Greenshields KN et al., 2009); however the ability of these antibodies to bind and exert pathogenic effects is inconsistent. Considering the presence of anti-GM1 antibody-negative axonal GBS cases, factors other than anti-GM1 antibodies need further investigation.

We characterized a DNA-binding protein from starved cells (Dps) derived from $C$. jejuni (Ishikawa T et al., 2003). This protein is produced at high levels under conditions of oxidative or nutritional stress, and efficiently protects bacterial DNA. We found that C-Dps 
induces paranodal myelin detachment and axonal degeneration of myelinated nerve fibers through selective binding with sulfatide (Piao H et al., 2010; Piao H et al., 2011). Sulfatide is essential for paranodal junction formation and for the maintenance of ion channels on myelinated axons (Honke $\mathrm{K}$ et al., 2002; Ishibashi $\mathrm{T}$ et al., 2002). In this study, we aimed to demonstrate invasion of C-Dps into hosts with $C$. jejuni-related GBS, both indirectly by showing antibody responses to C-Dps and directly by demonstrating the presence of C-Dps in the blood.

\section{METHODS}

\section{Patients and controls}

For studying IgG antibody responses to C-Dps, serum samples obtained from 42 patients with GBS, 148 patients with other inflammatory neurologic diseases (OIND), 11 patients with C. jejuni enteritis, all of whom had positive stool cultures, and 55 healthy controls (HC), were measured for their reactivity to recombinant C-Dps protein using an ELISA. We examined the blood samples obtained before immune-therapies. The demographics and clinical data of patients and healthy controls were shown in Table 1. GBS patients were electrophysiologically classified as axonal, demyelinating, unclassifiable, or unexcitable according to a reported criterion (Hadden RD, et al. 1998). Neurological severity was accessed by the Hughes grade (Hughes RA, et al. 1978). The presence of antibodies against $C$. jejuni was determined by ELISA using the SERION ELISA classic Campylobacter jejuni IgG kit (Virion/Serion, Würzburg, Germany), which has a sensitivity of $100 \%$ and a specificity of $83.6 \%$, according to the manufacturer's product information. 
Among the GBS patients, 24 were positive for anti-C. jejuni antibodies in sera by ELISA, and were classified as having C. jejuni-related GBS (stool cultures were negative in three of them), while the other 18 who had GBS following an upper respiratory tract infection were all seronegative. Among the 11 patients with $C$. jejuni enteritis, five (45.45\%) were also positive for anti-C. jejuni antibody by ELISA. The serum from nine patients with Miller Fisher syndrome (MFS) were also examined. The details of the patients with OIND are as follows: 79 patients had multiple sclerosis, 29 had HTLV-1-associated myelopathy/tropical spastic paraparesis, 25 had myelitis with atopic diathesis, six had chronic inflammatory demyelinating polyneuropathy and IgM antibody responses to C-Dps were also examined in six $C$. jejuni-related GBS patients, five patients with $C$. jejuni enteritis alone, and 10 HC. For detecting C-Dps in the blood, we analyzed the C-Dps levels of serum by sandwich ELISA in 42 GBS patients (27 with preceding C. jejuni infection and 16 with antecedent respiratory tract infection), 5 patients with $C$. jejuni enteritis alone, and $21 \mathrm{HC}$. The study procedures were approved by the ethics committee of the Graduate School of Medical Sciences, Kyushu University.

\section{Purification of recombinant C-Dps protein}

E. coli BL21 (DE3) cells harboring the $d p s$ gene were grown in LB-ampicillin $(50 \mu \mathrm{g} / \mathrm{ml})$ at $37^{\circ} \mathrm{C}$ overnight. After expression of $d p s$ was induced with $1 \mathrm{mM}$ isopropyl-D-thiogalactoside for $3 \mathrm{~h}$, bacterial cells were harvested $(15,000 \times g$ for $1 \mathrm{~h})$ and resuspended in $20 \mathrm{mM}$ Tris- $\mathrm{HCl}$ buffer ( $\mathrm{pH} 8.0)$. After cell disruption by sonication, the lysates were centrifuged at $4^{\circ} \mathrm{C}(39,000 \times g$ for $20 \mathrm{~min})$. Supernatants containing C-Dps 
were purified using Ni-NTA agarose columns and dialyzed against phosphate-buffered saline (PBS)-0.1 mM EDTA. ${ }^{12}$ Thereafter, endotoxin levels were decreased by affinity chromatography using a polymyxin B agarose gel (Sigma, St. Louis, MO). We assayed the endotoxin level in the final protein solution using a QCL-1000 kit (BioWhittaker, Verviers, Belgium), and the levels were found to be less than $10 \mathrm{EU} / \mathrm{mg}$.

\section{Western blotting for anti-C-Dps IgG antibodies}

C-Dps was electrophoresed on $15 \%$ sodium dodecyl sulfate-polyacrylamide electrophoresis gels and transferred onto a polyvinylidene fluoride membrane (GE Healthcare Bio-Sciences Corp., Piscataway, NJ). Membranes were blocked with 5\% skim milk in Tris-buffered saline- $0.2 \%$ Tween-20 (TBST) for $1 \mathrm{~h}$ at room temperature, and then washed three times with TBST. Serum specimens were diluted 1:100, added to membranes and incubated at $4^{\circ} \mathrm{C}$ overnight. After washing, a 1:10,000 diluted horseradish peroxidase (HRP)-conjugated mouse anti-human IgG antibody was added and the membranes were incubated at room temperature for $1 \mathrm{~h}$. Membranes were then washed and drained to remove excess liquid. Detection of protein was performed an enhanced chemiluminescence kit (GE Healthcare Bio-Sciences Corp.) and the membranes were exposed to X-ray film for $5 \mathrm{~min}$.

\section{ELISA for anti-C-Dps IgG and IgM antibodies}

We coated polystyrene microtiter ELISA plates (ICN Biomedicals, Inc., Costa Mesa, CA) with endotoxin-free C-Dps protein $(0.1 \mu \mathrm{g} /$ well $)$ overnight at $4{ }^{\circ} \mathrm{C}$. After washing the plates 
with $0.1 \%$ Tween-20 in PBS (PBST), non-specific binding sites were blocked by incubation with blocking buffer (Nacalai Tesque, Kyoto, Japan) at room temperature for 45 min. Fifty microliters of each serum sample, serially diluted 1:2,000 with blocking buffer in PBST, was applied to the wells at room temperature and incubated for $1 \mathrm{~h}$. After washing with PBST, $50 \mu 1$ of HRP-conjugated mouse anti-human IgG or IgM $(1: 2,000)$ (Southern Biotechnology Associates, Birmingham, AL) was applied to each well. We developed the plates using $100 \mu 1 /$ well o-phenylenediamine dihydrochloride (Sigma). After $15 \mathrm{~min}$, the reaction was blocked by the addition of $50 \mu \mathrm{l}$ of $2 \mathrm{M} \mathrm{H}_{2} \mathrm{SO}_{4}$ to each well. The optical density (OD) was quantified at $450 \mathrm{~nm}$ using an Immunomini NJ-2300 plate reader (Inter Med, Osaka, Japan). Each plate included negative and positive control sera. The cut-off level for the positive presence of the anti-C-Dps antibody was defined as the mean value plus five SD of the $\mathrm{OD}$ values of the $\mathrm{HC}$.

\section{ELISA for anti-ganglioside antibodies}

Bovine brain ganglioside type III (containing GM1, GD3, GD1a, GD1b, and GT1b), GM1, GM2, GM3, GD1a, GalNAc-GD1a, GD1b, GD3, sulfatide, GT1b, and galactocerebroside were purchased from Sigma and GQ1b was obtained from Calbiochem (Gibbstown, NJ). To detect antibodies to gangliosides in sera, gangliosides (GM1, GM2, GM3, GD1a, GD1b, GD3, GT1b, GQ1b, GalNAc-GD1a) (200 ng each) were placed in duplicate into 96-well microtiter ELISA plates and dried by evaporation. After incubation with $1 \%$ bovine serum albumin in PBS for $30 \mathrm{~min}, 50 \mu 1$ of each serum sample (1:40) was applied to the wells at room temperature and incubated for $1.5 \mathrm{~h}$ (Kusunoki S et al., 1994). After washing with 
PBS, $50 \mu 1$ of HRP-conjugated anti-human IgG (1:500) (ICN Biomedicals, Inc.) was applied to each well. We developed the plates using $200 \mu \mathrm{l} /$ well o-phenylenediamine dihydrochloride (Sigma). After 2 min, the reaction was blocked by the addition of $50 \mu 1$ of $4 \mathrm{M} \mathrm{H}_{2} \mathrm{SO}_{4}$ to each well. The OD was quantified at $490 \mathrm{~nm}$ using an Immunomini NJ-2300 plate reader (Inter Med). The cut-off level was set at 0.1 O.D. units for all gangliosides examined.

\section{Sandwich ELISA for the detection of C-Dps in serum}

We detected C-Dps in serum with a sandwich ELISA using two monoclonal anti-C-Dps antibodies. ELISA plates were coated with a monoclonal anti-C-Dps antibody ( $5 \mu \mathrm{g} / \mathrm{well})$ overnight at $4{ }^{\circ} \mathrm{C}$. After washing, non-specific binding sites were blocked by incubation with blocking buffer (Nacalai Tesque). Undiluted serum (50 $\mu 1 /$ well) was applied to wells and incubated for $1 \mathrm{~h}$. After washing with PBST, HRP-conjugated anti-C-Dps antibody $(1: 2,500)$ was applied to each well. We developed the plates using $50 \mu 1 /$ well o-phenylenediamine dihydrochloride (Sigma). After $15 \mathrm{~min}$, the reaction was blocked by the addition of $50 \mu \mathrm{l}$ of $4 \mathrm{~N} \mathrm{H}_{2} \mathrm{SO}_{4}$ to each well. The OD was quantified at $490 \mathrm{~nm}$. Each plate included negative and positive control sera. We generated a standard curve using the serially diluted recombinant C-Dps protein $(1.56-400 \mathrm{ng} / \mathrm{ml})$ and the slope of the fitting curve was 0.99 . The limit of detection was defined as the mean value plus three SD of the OD values of $\mathrm{HC}(44.61 \mathrm{ng} / \mathrm{ml})$ and used as a cut-off value.

\section{Statistical analysis}


Fisher's exact probability test or Chi-square test was employed for comparison of the frequencies of the anti-C-Dps antibody and the anti-ganglioside antibody in each group. Statistical significance was set at $p<0.05$.

\section{RESULTS}

\section{Clinical data of patients.}

The demographics and clinical data of patients and $\mathrm{HC}$ were shown in table1. The patients with GBS and OIND were significantly older than patients with $C$. jejuni enteritis alone (C. jejuni related GBS and OIND v.s. C. jejuni enteritis alone, $\mathrm{p}<0.05$; respiratory related GBS v.s. C. jejuni enteritis alone, $\mathrm{p}<0.01)$. As expected, the interval between an infectious onset and blood sampling in patients with GBS and MFS were significantly longer than that of patients with $C$. jejuni enteritis alone $(\mathrm{p}<0.05, C$. jejuni related GBS and respiratory related GBS v.s. $C$. jejuni enteritis alone; $\mathrm{p}<0.01$, MFS v.s. $C$. jejuni enteritis alone). Nerve conduction study classified 17 patients with $C$. jejuni related GBS and no patient with respiratory related GBS as axonal type. The electrophysiological phenotype (axonal, demyelinating, or the others) was significantly different between $C$. jejuni related and respiratory related GBS.

\section{Anti-C-Dps antibody in C. jejuni-related GBS patients}

We first analyzed the levels of serum IgG antibodies against recombinant C-Dps in 42 GBS patients (24 with preceding C. jejuni infection and 18 with antecedent respiratory tract infection), 11 patients with $C$. jejuni enteritis alone, 148 patients with OIND and 55 
HC, by ELISA. Anti-C-Dps IgG antibody was only detected in patients with $C$. jejuni infection and its frequency was significantly higher in $C$. jejuni-related GBS patients $(62.5 \%)$ than in $\mathrm{HC}(0 \% ; p<0.001)$, patients with OIND $(0 \% ; p<0.001)$, or $C$. jejuni enteritis patients without GBS (9\%; $p=0.004)$ (Fig. 1A). Neither patients with GBS following respiratory tract infection nor MFS patients had anti-C-Dps IgG antibodies. The presence of antibodies against C-Dps in $C$. jejuni-related GBS patients was also confirmed by western blotting (Fig. 1B). Anti-C-Dps IgM antibodies were detected in none of six $C$. jejuni-related GBS patients, five patients with $C$. jejuni enteritis alone, and $10 \mathrm{HC}$. Threre was no significant difference in the electrophysiological subtype between anti-C-Dps antibody positive and negative GBS patients.

\section{Anti-ganglioside antibody in C. jejuni-related GBS patients}

Anti-GM1 antibodies were found in $37.5 \%$ of $C$. jejuni-related GBS patients, and other anti-ganglioside antibodies were found in $20 \%$ of patients or fewer (Fig. 2). The frequency of anti-GM1 antibody presence was significantly higher in patients with $C$. jejuni-related GBS than in those with $C$. jejuni enteritis alone $(p=0.033)$. The frequency of anti-GD1b antibody presence tended to be higher in with $C$. jejuni-related GBS than in those with $C$. jejuni enteritis alone.

\section{Detection of C-Dps in sera from GBS patients}

The sera from five GBS patients with $C$. jejuni infection showed higher OD values than the cut-off value (Fig. 3). There was no patient who showed a higher serum OD value than 
the cut-off value in the respiratory infection GBS, C. jejuni enteritis, MFS, or HC groups. The frequency of positivity for C-Dps in the serum was significantly higher in $C$. jejuni-related GBS patients $(14.8 \%)$ than in $\mathrm{HC}(0 \% ; p=0.032)$. There was no significant difference in the electrophysiological classification between C-Dps positive and negative GBS patients.

\section{DISCUSSION}

We found that serum IgG antibodies against C-Dps were significantly more common in $C$. jejuni-related GBS patients than in HC or patients with OIND or C. jejuni enteritis.

Furthermore, C-Dps was detected in sera from $C$. jejuni-related GBS patients, but not in sera from $\mathrm{HC}$, patients with GBS following respiratory tract infection or those with $C$. jejuni enteritis. IgM antibodies against C-Dps were undetectable in patients with $C$. jejuni enteritis alone and C. jejuni-related GBS patients.

The presence of anti-C-Dps IgG antibodies in C. jejuni-infected patients indicates that C-Dps can be absorbed during C. jejuni infection and presented to the host immune system. The absence of IgM antibodies against C-Dps in patients with C. jejuni enteritis alone indicates that the delay in blood sampling from $C$. jejuni-related GBS patients, compared with that from patients with $C$. jejuni enteritis alone, is not a major reason for the specific positivity of the IgG response in $C$. jejuni-related GBS. The heightened immune response to C-Dps in $C$. jejuni-related GBS patients compared with the $C$. jejuni enteritis patients suggests that, in $C$. jejuni-related GBS patients, the host is more often and more heavily 
exposed to C-Dps, or that the immune response against C-Dps is exaggerated in those patients with GBS compared with those without GBS. In a previous experimental infection study (Li CY et al., 1996), the possible existence of a neurotoxin produced by the organism could not be excluded because of severe paralysis in the absence of apparent morphological changes and inflammation. In this model, diarrhea began 2-4 days after inoculation and lasted for up to 14 days, while the earliest signs of paralysis appeared 5 days after inoculation. C-Dps, which is liberated by bacterial cell lysis during the diarrhea period, may thus be a candidate neurotoxin produced by this organism.

Anti-GM1 antibody appears to be the most frequently found anti-ganglioside antibody in AMAN, and their specific response may be related to the severity. Although the sample size is small in this study, the frequency of anti-GM1 antibody presence in patients with $C$. jejuni-related GBS was significantly higher than that in patients with $C$. jejuni enteritis alone. Anti-GM1 antibody response is considered to play significant role in the pathogenesis of $C$. jejuni related GBS, but no consensus has emerged regarding the effects of anti-GM1 antibody treatment on myelinated axons in either isolated nerve preparations or following intraneural injection. Some authors have reported a conduction block and pathological changes (Takigawa T et al., 1995; Willison HJ et al., 1997; Susuki K et al., 2007; Greenshields KN et al., 2009), while others have not found these changes (Hirota N et al., 1997; Buchwald B et al., 1998; Dilley A et al., 2003). Such inconsistencies are considered to be attributable to the GM1 microenvironment in vivo, where GM1 epitopes are embedded and hidden (Greenshields KN et al., 2009).

The detailed mechanism of C-Dps contribution in GBS is unclear. We previously 
reported that C-Dps directly induces paranodal myelin detachment and axonal degeneration through binding to sulfatide in vivo and in vitro (Piao $\mathrm{H}$ et al., 2010). We also showed that C-Dps is a candidate neurotoxin and preferentially binds to the nodes of Ranvier, while we could not find the binding of recombinant anti-C-Dps antibody to the peripheral nerve (Piao H et al., 2011). We here showed direct evidences of C-Dps invasion into blood circulation and antibody response to C-Dps in vivo of C. jejuni related GBS patients. On these bases, we consider direct neurotoxic effects of C-Dps, potentially augmenting the actions of anti-GM1 antibodies by revealing hidden GM1 epitopes at the node, rather than a focal autoantibody response in the peripheral nerve. A considerable immune-mediated mechanism is that C-Dps firstly binds to the peripheral nerve and subsequent anti-C-Dps antibody binding to the C-Dps may cause peripheral nerve damage through activation of complements. Since we found no clear association between electrophysiological subtypes of GBS (axonal or demyelinating) and the positivity of C-Dps or anti-C-Dps antibody in this study, it needs further investigation to confirm an involvement of C-Dps in the mechanism of axonal pathology in C. jejuni related GBS.

\section{ACKNOWLEDGEMENT}

This work was supported in part by grants from the Ministry of Education, Culture, Sports, Science and Technology of Japan, a Neuroimmunological Disease Research Committee grant from the Ministry of Health, Labour and Welfare of Japan and a grant for Research on Brain Science. 


\section{REFERENCES}

Ariga T, Yu RK., 2005. Antiglycolipid antibodies in Guillain-Barré syndrome and related diseases: review of clinical features and antibody specificities. J. Neurosci. Res. 80, $1-17$.

Buchwald B, Toyka KV, Zielasek J, Weishaupt A, Schweiger S, Dudel J., 1998. Neuromuscular blockade by IgG antibodies from patients with Guillain-Barré syndrome: a macro-patch-clamp study. Ann. Neurol. 44, 913-922.

Dilley A, Gregson NA, Hadden RDM, Smith KJ., 2003. Effects on axonal conduction of anti-ganglioside sera and sera from patients with Guillain-Barré syndrome. J. Neuroimmunol. 139, 133-140.

Greenshields KN, Halstead SK, Zitman FMP, Rinaldi S, Brennan KM, O’Leary C, Chamberlain LH, Easton A, Roxburgh J, Pediani J, Furukawa K, Furukawa K, Goodyear CS, Plomp JJ, Willison HJ., 2009. The neuropathic potential of anti-GM1 autoantibodies is regulated by the local glycolipid environment in mice. J. Clin. Invest. $119,595-610$.

Griffin JW, Li CY, Ho TW, Xue P, Macko C, Gao CY, Yang C, Tian M, Mishu B, Cornblath DR., 1995. Guillain-Barré syndrome in northern China. The spectrum of neuropathological changes in clinically defined cases. Brain 118, 577-595.

Griffin JW, Li CY, Ho TW, Tian M, Gao CY, Xue P, Mishu B, Cornblath DR, Macko C, McKhann GM, Asbury AL., 1996a. Pathology of the motor-sensory axonal Guillain-Barré syndrome. Ann. Neurol. 1996 39, 17-28. 
Hadden RD, Cornblath DR, Hughes RA, Zielasek J, Hartung HP, Toyka KV, Swan AV. Electrophysiological classification of Guillain-Barré syndrome: clinical associations and outcome. Plasma Exchange/Sandoglobulin Guillain-Barré Syndrome Trial Group. Ann Neurol. 1998 44, 780-788.

Hiraga A, Kuwabara S, Ogawara K, Misawa S, Kanesaka T, Koga M, Yuki N, Hattori T, Mori M., 2005. Patterns and serial changes in electrodiagnostic abnormalities of axonal Guillain-Barré syndrome. Neurology 64, 856-860.

Hirota N, Kaji R, Bostock H, Shindo K, Kawasaki T, Mizutani K, Oka N, Kohara N, Saida T, Kimura J., 1997. The physiological effect of anti-GM1 antibodies on saltatory conduction and transmembrane currents in single motor axons. Brain 120, 2159-2169.

Ho TW, Mishu B, Li CY, Gao CY, Cornblath DR, Griffin JW Asbury AK, Blaser MJ, McKhann GM., 1995. Guillain-Barré syndrome in northern China. Relationship to Campylobacter jejuni infection and anti-glycolipid antibodies. Brain 118, 597-605. Honke K, Hirahara Y, Dupree J, Suzuki K, Popko B, Fukushima K, Fukushima J, Nagasawa T, Yoshida N, Wada Y, Taniguchi N., 2002. Paranodal junction formation and spermatogenesis require sulfoglycolipids. Proc. Natl. Acad. Sci. USA. 99, 4227-32.

Hughes RA, Newsom-Davis JM, Perkin GD, Pierce JM., 1978. Controlled trial prednisolone in acute polyneuropathy. Lancet 2, 750-753.

Ishibashi T, Dupree JL, Ikenaka K, Hirahara Y, Honke K, Peles E, Popko B, Suzuki K, Nishino H, Baba H., 2002. A myelin galactolipid, sulfatide, is essential for maintenance of ion channels on myelinated axon but not essential for initial cluster 
formation. J. Neurosci. 22, 6507-6514.

Ishikawa T, Mizunoe Y, Kawabata S, Takade A, Harada M, Wai SH, Yoshida S., 2003. The iron-binding protein Dps confers hydrogen peroxide stress resistance to Campylobacter jejuni. J. Bacteriol. 185, 1010-7.

Kusunoki S, Chiba A, Kon K, Ando S, Arisawa K, Tate A, Kanazawa I., 1994. $\mathrm{N}$-acetylgalactosaminyl GD1a is a target molecule for serum antibody in Guillain-Barré syndrome. Ann. Neurol. 35, 570-576.

Kuwabara S, Ogawara K, Misawa S, Koga M, Hiraga A, Kanesaka T, Hattori T, Yuki N., 2004. Does Campylobacter jejuni infection elicit "demyelinating” Guillain-Barré syndrome? Neurology 63, 529-533.

Li CY, Xue P, Tian WQ, Liu RC, Yang C., 1996. Experimental Campylobacter jejuni infection in the chicken: an animal model of axonal Guillain-Barré syndrome. J. Neurol. Neurosurg. Psychiatry 61, 279-284.

Ogawara K, Kuwabara S, Mori M, Hattori T, Koga M, Yuki N., 2000. Axonal Guillain-Barré syndrome: relation to anti-ganglioside antibodies and Campylobacter jejuni infection in Japan. Ann. Neurol. 48, 624-631.

Piao H, Minohara M, Kawamura N, Li W, Mizunoe Y, Umehara F, Goto Y, Kusunoki S, Matsushita T, Ikenaka K, Maejima T, Nabekura J, Yamasaki R, Kira J., 2010. Induction of paranodal myelin detachment and sodium channel loss in vivo by Campylobacter jejuni DNA-binding protein from starved cells (C-Dps) in myelinated nerve. J. Neurol. Sci. 288, 54-62.

Piao H, Minohara M, Kawamura N, Li W, Matsushita T, Yamasaki R, Mizunoe Y, Kira J., 
2011. Tissue binding patterns and in vitro effects of Campylobacter jejuni DNA-binding protein from starved cells. Neurochem. Res. 36, 58-66.

Sheikh KA, Zhang G., Gong Y, Schnaar RL, Griffin JW., 2004. An anti-ganglioside antibody-secreting hybridoma induces neuropathy in mice. Ann. Neurol. 56, 228-239.

Susuki K, Rasband MN, Tohyama K, Koiuchi K, Okamoto S, Funakoshi K, Hirata K, Baba H, Yuki N., 2007. Anti-GM1 antibodies cause complement-mediated disruption of sodium channel clusters in peripheral motor nerve fibers. J. Neurosci. 27, 3956-3967.

Takigawa T, Yasuda H, Kikkawa R, Shigeta Y, Saida T, Kitasato H., 1995. Antibodies against $\mathrm{GM}_{1}$ ganglioside affect $\mathrm{K}^{+}$and $\mathrm{Na}^{+}$currents in isolated rat myelinated nerve fibers. Ann. Neurol. 37, 436-42.

Willison HJ, O’Hanlon G, Paterson G, O’Leary CP, Veitch J, Wilson G, Roberts M, Tang T, Vincent A., 1997. Mechanisms of action of anti-GM $\mathrm{GM}_{1}$ and anti-GQ $\mathrm{G}_{1 \mathrm{~b}}$ ganglioside antibodies in Guillain-Barré syndrome. J. Infect. Dis. 176, S144-119. 


\section{Figure Legends}

Fig. 1 (A) ELISA for IgG antibodies against recombinant C-Dps in sera. The short lines denote mean values for the respective groups. The long dashed line across the panel denotes absorbance values five SD above the mean value in healthy controls. (B) Western blotting analyses for C-Dps. Anti-C-Dps antibody (lane 1) and sera from patients with $C$. jejuni-related GBS (lanes 2 and 3) react with recombinant C-Dps, but those from healthy controls do not (lanes 4 and 5). AM = myelitis with atopic diathesis, $\mathrm{C}$-Dps $=$ Campylobacter jejuni DNA-binding protein from starved cells, CIDP = chronic inflammatory demyelinating polyneuropathy, GBS = Guillain-Barré syndrome, HAM = HTLV-I-associated myelopathy/tropical spastic paraparesis, HCs = healthy controls, MFS $=$ Miller Fisher syndrome, $\mathrm{MS}=$ multiple sclerosis, O.D. $=$ optical density.

Fig. 2 The frequencies of anti-ganglioside $\operatorname{IgG}$ antibody presence in patients with $C$. jejuni-related GBS $(\mathrm{G} ; n=24)$ and $C$. jejuni enteritis patients without GBS $(\mathrm{E} ; n=11)$.

Fig. 3 Sandwich ELISA for the detection of C-Dps in sera. The short lines denote mean values for the respective groups. The long dashed line across the panel denotes absorbance values three $\mathrm{SD}$ above the mean value in healthy controls. GBS = Guillain-Barré syndrome, MFS = Miller Fisher syndrome, O.D. = optical density 
Table 1. Demographics and neuropathic characteristics of patients and healthy controls

\begin{tabular}{|c|c|c|c|c|c|c|}
\hline & $\begin{array}{l}C . \text { jejuni } \\
\text { related GBS } \\
\quad(\mathrm{n}=24)\end{array}$ & $\begin{array}{l}\text { Respiratory } \\
\text { related GBS } \\
\quad(\mathrm{n}=18)\end{array}$ & $\begin{array}{l}\text { MFS } \\
(n=9)\end{array}$ & $\begin{array}{l}\text { C. jejuni } \\
\text { enteritis } \\
(\mathrm{n}=11)\end{array}$ & $\begin{array}{l}\text { OIND } \\
(\mathrm{n}=139)\end{array}$ & $\begin{array}{c}\mathrm{HC} \\
(\mathrm{n}=50)\end{array}$ \\
\hline Age, y & $\begin{array}{c}42.0 * \\
(13-68)\end{array}$ & $\begin{array}{l}52.8 * * \\
(27-78)\end{array}$ & $\begin{array}{c}39.0 \\
(12-59)\end{array}$ & $\begin{array}{c}16.4 \\
(5-38)\end{array}$ & $\begin{array}{c}46.7^{*} \\
(12-77)\end{array}$ & $\begin{array}{c}44.5 \\
(21-62)\end{array}$ \\
\hline $\begin{array}{l}\text { Sex } \\
\text { (Male / Female) }\end{array}$ & $16 / 8$ & $7 / 11$ & $8 / 1$ & $7 / 4$ & $44 / 95$ & $6 / 44$ \\
\hline $\begin{array}{l}\text { Infectious onset } \\
\text { to blood } \\
\text { sampling, d }\end{array}$ & $\begin{array}{l}13.8 * \\
(7-24)\end{array}$ & $\begin{array}{l}14.0 * \\
(6-24)\end{array}$ & $\begin{array}{l}19.0 * * \\
(9-32)\end{array}$ & $\begin{array}{c}5.0 \\
(1-7)\end{array}$ & N/A & N/A \\
\hline $\begin{array}{l}\text { Neurological } \\
\text { onset to blood } \\
\text { sampling, d }\end{array}$ & $5.8(1-14)$ & $6.0(2-10)$ & $5.7(2-21)$ & $\mathrm{N} / \mathrm{A}$ & N/A & N/A \\
\hline Hughes grade & $3.2(1-4)$ & $3.5(2-5)$ & $\mathrm{N} / \mathrm{A}$ & $\mathrm{N} / \mathrm{A}$ & N/A & $\mathrm{N} / \mathrm{A}$ \\
\hline $\begin{array}{l}\text { Phenotype } \\
\text { (axonal } \\
\text { / demyelinating } \\
\text { / the others) }\end{array}$ & $16 / 3 / 5^{* * *}$ & $3 / 8 / 7$ & N/A & $\mathrm{N} / \mathrm{A}$ & N/A & N/A \\
\hline
\end{tabular}

Data were expressed as a mean and range.

${ }^{*} \mathrm{p}<0.05$, v.s. $C$. jejuni enteritis; ${ }^{* *} \mathrm{p}<0.01$, v.s. C. jejuni enteritis; $* * * \mathrm{p}<0.01$, v.s. respiratory related GBS.

N/A, not applicable, The others include unclassifiable and unexcitable. 
Fig. 1

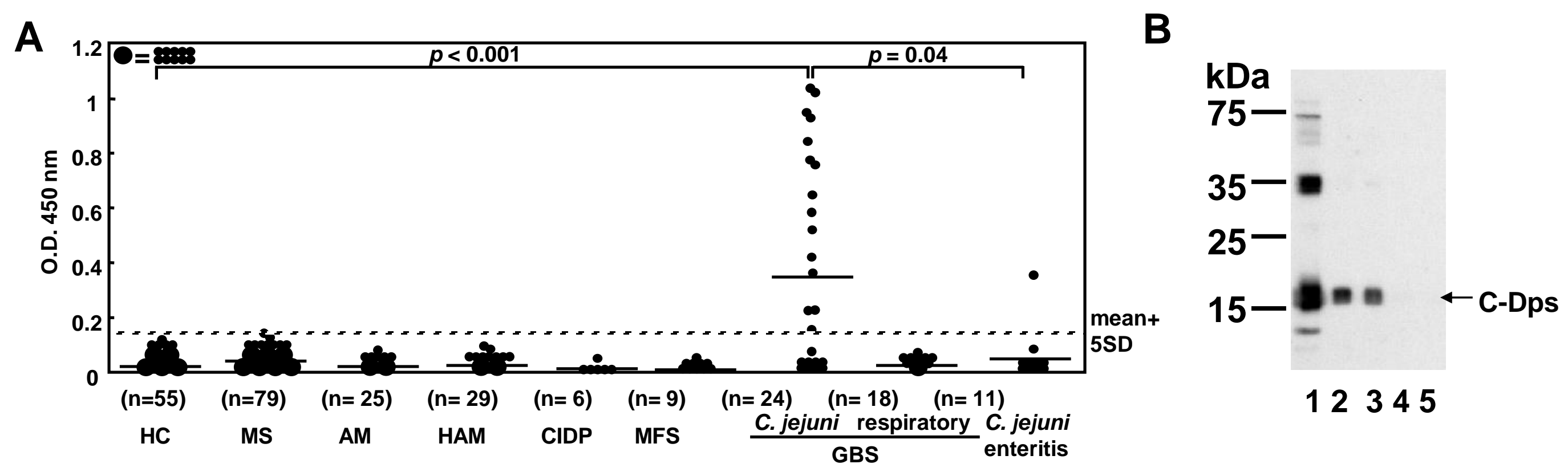


Fig. 2

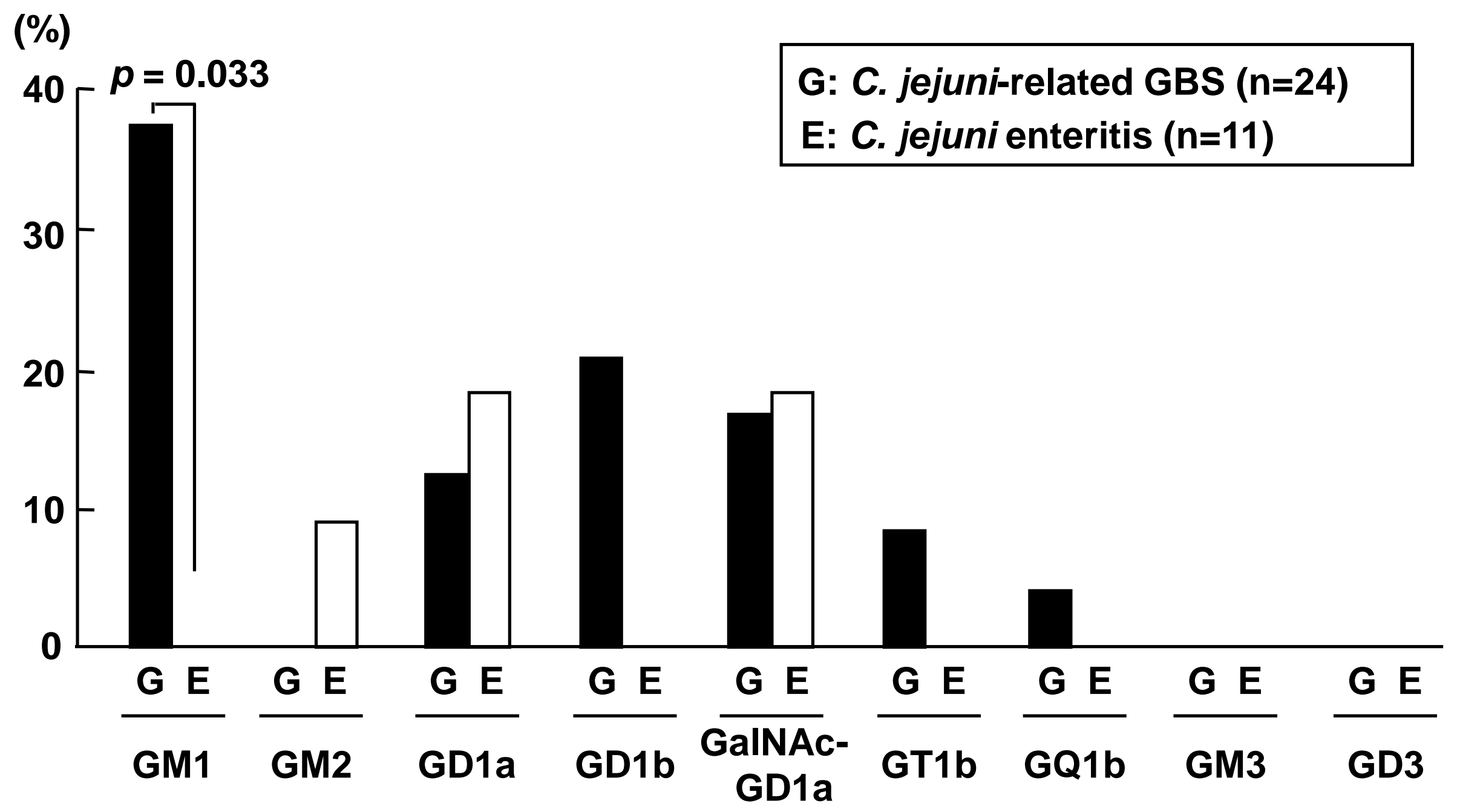


Fig. 3

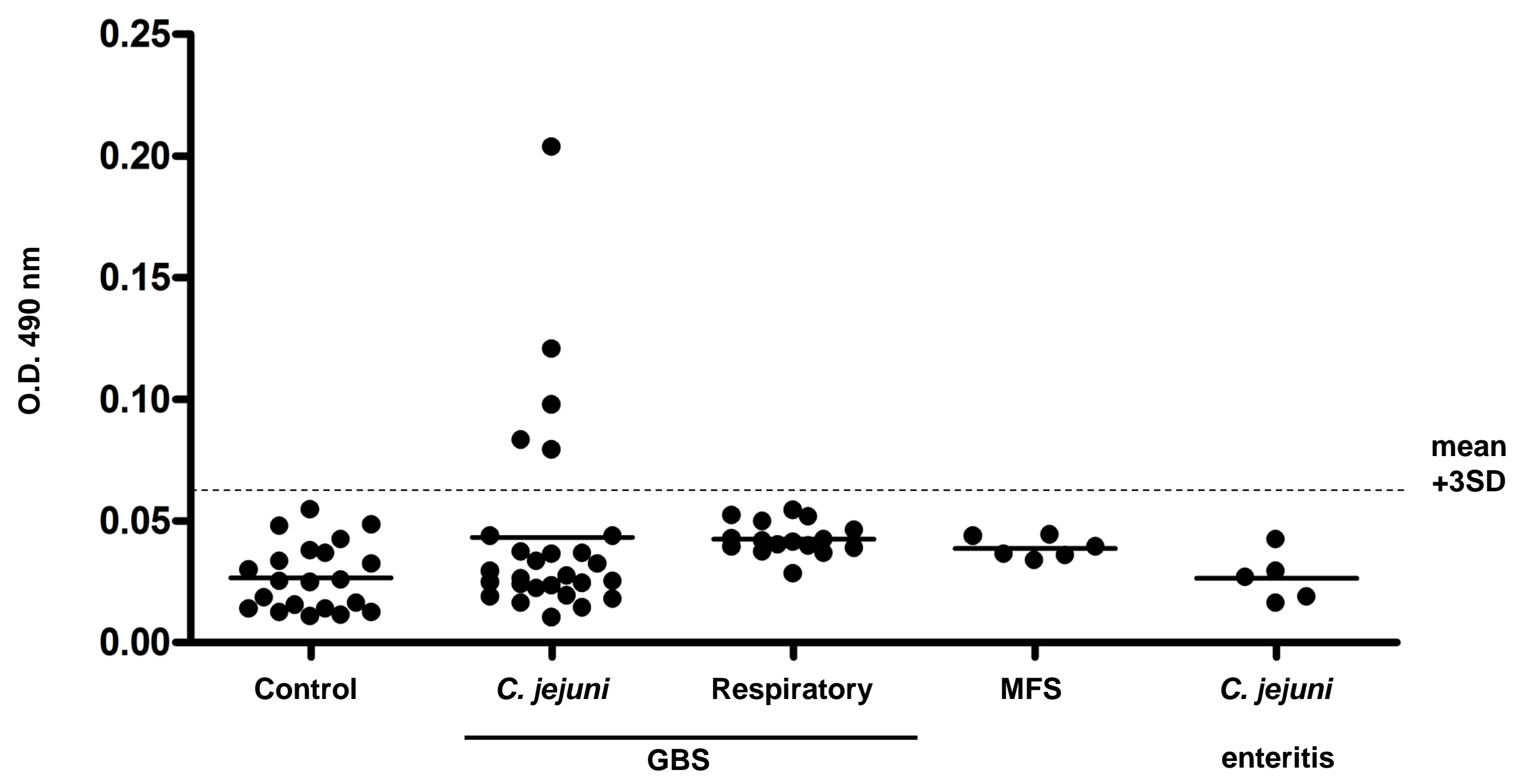

